\title{
关于开展健康城市建设的一点思考和认识
}

\author{
李立明
}

北京大学公共卫生学院, 北京 100083

E-mail:1mlee@bjmu.edu.cn

最近我了解Lancet杂志将发表清华大学关于中国健康 城市建设的特邀报告 ${ }^{[1]}$, 同时我也连续参加了国家卫生和 计划生育委员会(简称国家卫计委)全国爱国卫生运动委员 会办公室(简称全国爱卫办)组织的健康城市建设相关工作 研讨会, 学习了《关于开展健康城市健康乡镇建设的指导意 见》(http://www.nhfpc.gov.cn/jkj/s5898/201608/3a61d95e1f8d 49ffbb12202eb4833647.shtml)和《全国爱卫办关于开展健康 城市试点工作的通知》(http://www.nhfpc.gov.cn/jkj/s5898/ 201611/f1cb9ed675274c0fab49a87410ce9e20.shtml) 以及正在 修改完善中的《健康城市评价指标体系》等文件, 十分欣 喜和兴奋. 这是我国公共卫生工作者梦㻗以求的健康促进 的重大举措, 是我国爱国卫生运动科学、可持续发展的创 新性载体. 在国家卫计委和全国爱卫办的领导下, 全国专 家积极献计献策, 大量阅读文献, 深人开展调研, 拿出符 合国情、具有中国特色的工作方案. 为此, 作为原卫生部 爱卫办专家委员会的副主任委员, 我想谈一点个人的想法 和建议.

\section{1 开展健康城市建设的重要意义}

开展健康城市建设有以下几方面的重要意义: (1) 是 中国特色的健康促进工作的重要组成部分, 是全社会动 员、全民参与、多部门协作, 共同创造一个促进和维护健 康环境的完美展示; (2) 是中国特色的爱国卫生运动的重 要工作内容和卫生城市建设的科学延续和不断完善的重 要载体; (3) 是健康政策融人所有领域的重要体现, 通过 健康城市建设可以更好地展现这一政策的长远意义和科 学价值; (4) 是现代国际健康促进项目的伟大实践, 在发 展中国家如何践行健康促进理念, 是人类面临的共同挑 战. 我们要拿出中国范例; (5) 是落实中央全面建设小康
社会, 建设健康中国的重要抓手.

\section{2 健康城市的定义和特征}

世界卫生组织(World Health Organization, WHO)给出 的健康城市概念是：由健康的人群、健康的环境和健康的 社会有机结合发展的一个整体. 应该能改善其环境，扩大 其资源，使居民互相支持，发挥最大潜能 (http://www. nhfpc.gov.cn/jkj/s5898/201611/f1cb9ed675274c0fab49a87410 ce9e20.shtml).

WHO给出了健康城市具体的 10 条标准(略 $)^{[2,3]}$. 我理 解健康城市的核心特征应该包括：(1) 制定健康的公共政 策; (2) 创造健康的支持性环境(建成环境的硬件环境和人 文素养的软环境); (3) 强调社区行动(集体行动); (4) 发展 个人技能(养成良好的生活方式和行为习惯); (5) 调整卫生 服务方向(社会公平、公正); (6) 促进对健康的社会责任(政 府主导、法律法规保证); (7) 加大投资力度; (8) 巩固和拓 展健康伙伴关系；(9) 提高社区能力(社会动员、资源分配 和管理); (10) 建立健康促进的有力保障.

\section{3 健康城市指标的制定}

根据上述健康城市的定义和特征, 针对性地制定健 康城市评价指标体系. 针对全国爱国卫生运动委员会确定 的健康城市建设的五大内容：营造健康环境、优化健康服 务、构建健康社会、培育健康人群和发展健康文化, 从条 件指标、地域指标、效果指标和综合指标 4 个维度开展评 价. 相信在国家卫计委和各位专家的共同努力下, 中国健 康城市建设必然成为我国健康中国建设中健康环境建设 的重要组成部分, 并在健康中国建设中发挥积极的作用.

\section{参考文献}

1 Yang J, José G S, Remais J V, et al. The Tsinghua-Lancet Commission on Healthy Cities in China: Unlocking the power of cities for a healthy China. Lancet, 2018, http://dx.doi.org/10.1016/S0140-6736(18)30486-0

2 Hancock T, Duhl L. Promoting Health in the Urban Context. WHO Healthy Cities Papers. No. 1. Copenhagen: FADL Publisher, 1988

3 WHO Healthy Cities Project. A Guide to Assessing Healthy Cities. WHO Healthy Cities Papers No.3. Copenhagen: FADL Publishers, 1988 